\title{
Research on Safety Risk Assessment of Construction of Large Formwork Based on Fuzzy Bayesian Network
}

\author{
Yijing Peng \\ School of Management \\ Wuhan University of Science and Technology \\ Wuhan, Hubei, China,430081 \\ 19963595@qq.com
}

Keywords: Risk assessment; tall template; Bayesian network; fuzzy comprehensive evaluation

\begin{abstract}
In view of the fact that the existing large template construction accidents are complicated, combined with the project examples, we have established the risk evaluation index system of the tall template construction, and identified the dangerous sources during the construction of the tall template.In this paper, Bayesian network was combined with fuzzy comprehensive evaluation method, and combined with the actual project carried out the construction risk assessment, the results show that the method has a reasonable applicability, can be used for managers in the construction risk assessment reference.
\end{abstract}

\section{Introduction}

With the rapid development of China's economy, a variety of high-level, high-rise, large space building emerging.In the construction process, due to a lot of unsafe factors, such buildings are likely to cause instability collapse of security incidents, resulting in death and death to the country and people's lives and property caused significant losses.Every incident occurred, we are warned to find out the reasons to solve the problem, for the construction industry health, safety and rapid development contribute.Therefore, it is necessary to study the risk assessment of dangerous sources during the construction of tall template works as a major hazard source of construction site.

Domestic and foreign scholars have studied the risk analysis of load and construction safety accidents during the construction of tall template. Rosowsky [1] measured the load on the site of the cast-in-place reinforced concrete structure under construction and found that its maximum load was $50 \mathrm{KN} / \mathrm{m}^{2}$.

On the basis of collecting the sample data, Xie Nan[2] gives the statistical data of the load of the template engineering construction and the concrete dead load.Zhao Jun [3] pointed out that the structure of the load distribution in the process can be described as an exponential distribution and the relevant parameters of the estimated, and finally given the proposed value of the live standard value. Hadipriono [4] studied the causes of multiple scaffolding accidents in the United States, and divided the causes of scaffolding accidents into external factors and internal factors.Such as damage caused by impact load on the local part of the stent, removal of the frame during the construction of the accident caused by improper collapse of the accident; Internal causes include: structural accidents due to design factors and construction factors, such as the design does not fully consider the various construction process of accidental induced load, pole bearing capacity, horizontal bar and scissors support the number of insufficient overlap and so on.Fan Liangyi [5] through the accident tree analysis of high-support model construction safety of the weak links were systematically analyzed for the prevention and control of large template support system security incidents, to provide effective basis.Zhang Tao [6] proposed the use of gray theory on the impact of high-profile 
construction safety assessment of many factors to identify the main factors affecting the safety of the system.

Fault tree analysis can be based on a system-specific accident or failure to the results of layers to analyze the cause of the accident, conditions, at the same time can identify the accident or failure of the risk source,It can be used at all stages of the project implementation as needed.Pearl's Bayesian network technology proposed in 1986 [7] has similarity with the accident tree in the reasoning mechanism. The Bayesian network has a great advantage in solving the uncertainties of complex systems, so it can be widely used in many fields. This two methods can be easily converted.Therefore, this paper uses Bayesian network formed by fault tree transformation and fuzzy comprehensive evaluation method, and puts forward the fuzzy comprehensive evaluation method of construction risk and the construction risk of high-support model based on Bayesian network,

\section{Method of Safety Risk Identification and Evaluation for Construction of Large Formwork}

\subsection{Bayesian Network Model for Constructing Large Template Construction Accidents}

In this paper, Bayesian network technology is used to transform the accident tree, and the Bayesian network reasoning software GenIe2.0 is used to analyze.

According to the top event, intermediate event, bottom event and logic gate in the analysis method of the accident tree, it corresponds to the node and connection probability in the Bayesian network respectively.The accident tree model is transformed into Bayesian network model 1.

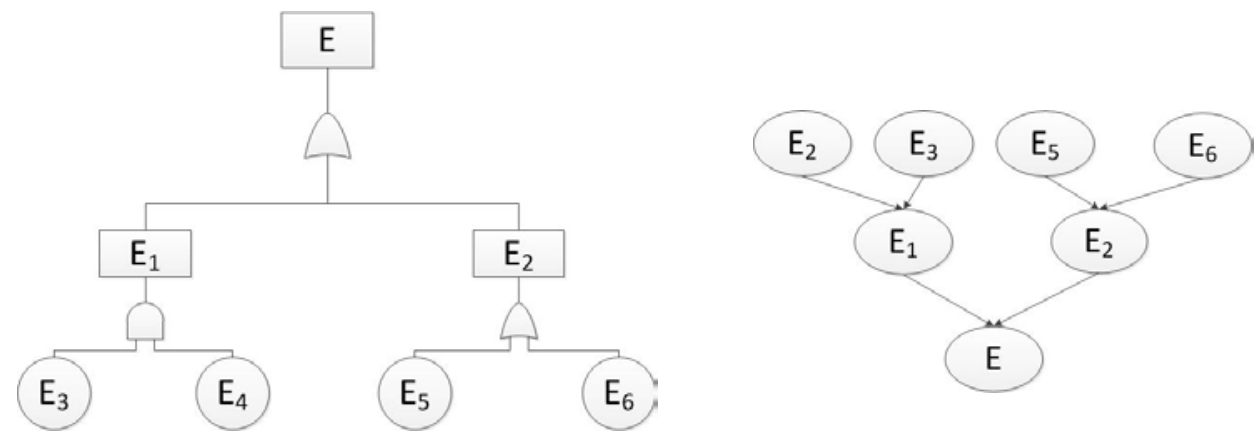

Fig.1 Transformation of accident tree to Bayesian network

\subsection{Fuzzy Comprehensive Evaluation of Risk Event Loss}

Risk loss refers to the template project in the event of a risk event in the event of a variety of consequences,including the safety of construction workers, economic property, the quality of the project, the construction period and the impact of the natural environment, the performance of the value of the loss of various sizes.In this paper, the calculation of each risk loss value is carried out by fuzzy comprehensive evaluation based on AHP [8].

\subsubsection{Establish factor sets}

According to the risk hierarchy index of the construction model of the tall construction project, the factor set $U=\left\{u_{1}, u_{2}, \cdots, u_{n}\right\}$ needed for the assessment is determined according to the risk hierarchy of the index system, and the single factor subset is: $U_{i}=\left\{u_{11}, u_{12}, \cdots, u_{1 m}\right\}, m$ is the number of indicators.

\subsubsection{Establish an evaluation set and quantify it}

The evaluation results of the evaluation of the risk of the risk of the fuzzy, $V=\left\{\mathrm{v}_{1}, \mathrm{v}_{2}, \cdots, \mathrm{v}_{\mathrm{n}}\right\}, n$ is the number of evaluation levels, generally according to the actual situation it can be divided into four or five levels of evaluation level.In this paper, the risk loss level is divided into five levels, as shown in Table 1. 
Table 1 Risk Loss Rating

\begin{tabular}{cccccc}
\hline Risk level & $\begin{array}{c}\mathrm{V} 1= \\
\text { Ignorable }\end{array}$ & $\mathrm{V} 2=$ slight & $\mathrm{V} 3=$ serious & V4= disaster & $\begin{array}{c}\mathrm{V} 5= \\
\text { Catastrophe }\end{array}$ \\
$\begin{array}{c}\text { Evaluation set } \\
\text { quantification }\end{array}$ & 0.050 & 0.125 & 0.200 & 0.275 & 0.350 \\
\hline
\end{tabular}

2.2.3 Determine the need to assess the risk factors on the evaluation of the weight of the object

In this paper, AHP method, through the discriminant matrix pairs of risk factors,the eigenvalues $\lambda_{\max }$ and their corresponding eigenvectors are solved,get the relative weight of each element of each criterion layer,and finally have the lowest level element for the overall goal of the sort weight. Then through the necessary consistency test of the judgment matrix,the discriminant matrix is usually checked by the consistency indicator $C I=\frac{\lambda_{\max }-n}{n-1}$, in order to obtain the allowable range of inconsistency, Saaty has introduced random consistency index RI. Through the table to determine the calculation of the consistency ratio of $C R=\frac{C I}{R I}$ again on the matrix consistency test, $R I$ as shown in Table 2

Table 2 Average random consistency index RI

\begin{tabular}{cccccccccccc}
\hline$n$ & 1 & 2 & 3 & 4 & 5 & 6 & 7 & 8 & 9 & 10 & 11 \\
$R I$ & 0 & 0 & 0.58 & 0.90 & 1.12 & 1.24 & 1.32 & 1.41 & 1.45 & 1.49 & 1.51 \\
\hline
\end{tabular}

When $C R \leq 0.1$, the consistency of the matrix is acceptable; When $C R>0.1$, if the consistency of the matrix A does not meet the requirements, you need to re-invite the experts to do re-evaluation until passing the inspection.So you can draw the first level of evaluation factors on the overall goal of the weight, it is also possible to derive the weight of the elements $W_{i}$ of the second level in the first layer.

2.2.4 Establish a single factor evaluation matrix

After constructing the hierarchical fuzzy subset, we quantify each factor, that is, each Ri matrix determines the membership degree of the evaluation object to each level fuzzy subset, and finally get the fuzzy relation matrix $\mathrm{R}$.

$$
R_{i}=\left[\begin{array}{cccc}
r_{11} & r_{12} & \cdots & r_{1 n} \\
r_{21} & r_{22} & \cdots & r_{2 n} \\
\cdots & \cdots & \ddots & \cdots \\
r_{m 1} & r_{m 2} & \cdots & r_{m n}
\end{array}\right]
$$

2.2.5 Fuzzy comprehensive evaluation and determine the final evaluation score

The weight vector $W i$ of each factor is obtained by combining the fuzzy synthesis operator with the fuzzy relation matrix to obtain the evaluation result vector B.In this paper, the weighted average operator is used as the operator of the evaluation process.

$$
B_{i}=W_{i} \cdot R_{i}=\left(a_{1}, a_{2}, \cdots, a_{m}\right)\left[\begin{array}{cccc}
r_{11} & r_{12} & \cdots & r_{1 n} \\
r_{21} & r_{22} & \cdots & r_{2 n} \\
\cdots & \cdots & \ddots & \cdots \\
r_{m 1} & r_{m 2} & \cdots & r_{m n}
\end{array}\right]=\left(b_{1}, b_{2}, \cdots b_{n}\right) \text {, Finally, the membership matrix }
$$

of the risk factors can be obtained, and then the loss value of each risk is obtained according to $C_{B_{\mathrm{i}}}=B_{i} \cdot V^{T}$. 


\subsection{Risk rating criteria}

The design of risk assessment in tall engineering project is: $\mathrm{R}=\mathrm{P} \times \mathrm{C}$ is risk calculation, $\mathrm{R}$ is the risk value of the risk factor, $\mathrm{P}$ is the probability value of the risk, $\mathrm{C}$ is the degree of loss of risk consequences. The actual construction situation, through the quantitative data on the specific high-scale construction project to determine the risk situation and determine the level of its risk level. As shown in Table 3, the overall risk level of construction is divided after the level of risk and risk loss has been identified.

Table 3 Risk Rating Table

\begin{tabular}{|c|c|c|c|c|c|}
\hline $\begin{array}{l}\text { Risk } \\
\text { Level }\end{array}$ & $\begin{array}{c}\text { Class I } \\
\text { (extremely dangerous) }\end{array}$ & $\begin{array}{c}\text { Class II } \\
\text { (highly dangerous) }\end{array}$ & $\begin{array}{c}\text { Class III } \\
\text { (generally dangerous) }\end{array}$ & $\begin{array}{c}\text { Class IV } \\
\text { (slightly dangerous) }\end{array}$ & $\begin{array}{c}\text { Class V } \\
\text { (dangerous and negligible) }\end{array}$ \\
\hline R Value & $\gg 0.8$ & $0.5 \sim 0.8$ & $0.1 \sim 0.5$ & $0.01 \sim 0.1$ & $\ll 0.01$ \\
\hline
\end{tabular}

\section{Case Study of Hazardous Source Risk Assessment Model Based on Fuzzy Bayesian Formwork}

This chapter takes the coal industry Jinan Design and Research Institute Co., Ltd. as an example, through the identification of the hazard source of the system, the fuzzy risk assessment based on the fuzzy Bayesian network is carried out for the tall template project using the above evaluation model.

\subsection{Risk Event List and Bottom Event Probability}

This paper investigates the way through the expert questionnaire, and the expert group composed of professionals scores the basic event risk probability of the tall template construction. As is shown in Table 4.

Table 4 High template construction risk event list and bottom event probability

\begin{tabular}{|c|c|c|}
\hline Code & Name Code & $\begin{array}{c}\text { Risk } \\
\text { Probability }\end{array}$ \\
\hline $\bar{A}$ & High-profile construction accident occurred & 0.26 \\
\hline B1 & Template design and preparation & 0.34 \\
\hline $\mathrm{C} 12$ & Template load parameter is incorrect & 0.36 \\
\hline $\mathrm{C} 13$ & Support system structure set unreasonable & 0.25 \\
\hline C14 & Without expert expert argument & 0.46 \\
\hline C15 & $\begin{array}{l}\text { Template project is not compiled construction organization design and safety } \\
\text { technical measures }\end{array}$ & 0.34 \\
\hline B2 & Template installation & 0.35 \\
\hline $\mathrm{C} 21$ & Operation, the template and accessories free to stack & 0.35 \\
\hline $\mathrm{C} 22$ & C22 Construction material failed & 0.53 \\
\hline $\mathrm{C} 23$ & $\begin{array}{l}\text { Not according to the design, construction organization design, safety } \\
\text { technical measures and other requirements of the construction }\end{array}$ & 0.33 \\
\hline $\mathrm{C} 24$ & Foundation Treatment Improper & 0.36 \\
\hline $\mathrm{C} 25$ & Model intermittent does not temporarily fix the template & 0.26 \\
\hline $\mathrm{C} 26$ & Eccentric load & 0.55 \\
\hline B3 & $\begin{array}{l}\text { Template removal C31 template when the concrete strength can not } \\
\text { withstand the removal of this load }\end{array}$ & 0.27 \\
\hline C32 & $\begin{array}{c}\text { Demolition of the order and method does not follow the design requirements } \\
\text { of the template }\end{array}$ & 0.46 \\
\hline
\end{tabular}

\subsection{Establishment of Bayesian Network Model for Construction of High - support Mold}

According to the rule of the failure tree to Bayesian network transformation, Bayesian network model of scaffolding collapse accident was established by Bayesian simulation software Genie2.0. as is shown in figure 2 . 


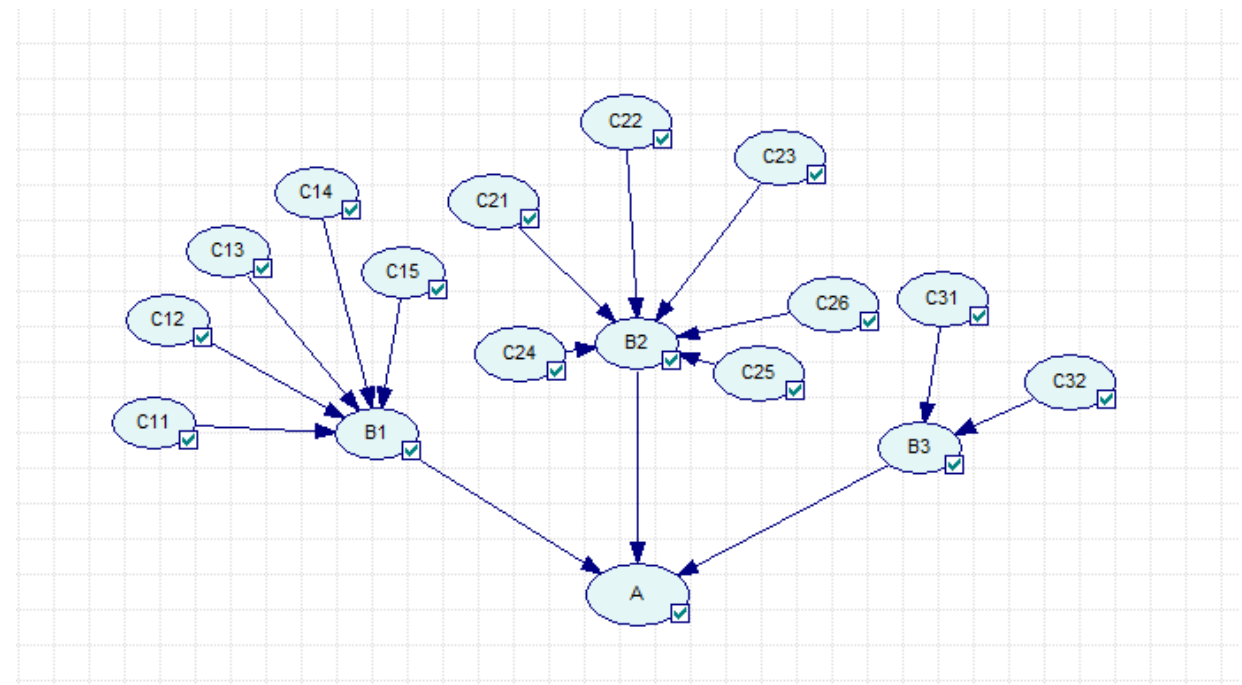

Figure 2 High template construction safety risk Bayesian network

\subsection{Probability reasoning of risk events}

The probability of basic events in Bayesian networks can be calculated by Genie2.0 software, the connection probability of each node in Table 4 is input into GeNIe software, click on the Update GeNIe will automatically calculate the probability of each node, and finally calculate the probability of occurrence of various types of risk events,As is shown in Table 5.

Table 5 Post-test results of various risk situations and overall risk profiles

\begin{tabular}{llll}
\hline Posterior probability & $\mathrm{A}$ & $\mathrm{B}_{1} \mathrm{~B}_{2}$ & $\mathrm{~B}_{3}$ \\
\hline $\mathrm{Y}$ & 0.448 & 0.551 & 0.273 \\
$\mathrm{~N}$ & 0.602 & 0.552 & 0.727 \\
\hline
\end{tabular}

\subsection{Loss of risk events}

Using the fuzzy comprehensive evaluation method described above, according to each risk even, $R_{i}$ can be obtained for the corresponding risk event loss evaluation score.

among them:

$\mathrm{W}_{A-B}=\left[\begin{array}{lll}0.143 & 0.714 & 0.143\end{array}\right]$

$\mathrm{W}_{B_{1}}=\left[\begin{array}{lllll}0.109 & 0.368 & 0.207 & 0.207 & 0.109\end{array}\right]$

$\mathrm{W}_{B_{2}}=\left[\begin{array}{llllll}0.043 & 0.067 & 0.067 & 0.230 & 0.362 & 0.230\end{array}\right]$

$\mathrm{W}_{B_{3}}=\left[\begin{array}{ll}0.750 & 0.250\end{array}\right]^{T}$

Each judgment matrix in the calculation process passed the consistency test, so the calculated sort weight is acceptable.Template design and preparation risk membership matrix.

$R_{1}=\left[\begin{array}{lllll}0.20 & 0.60 & 0.20 & 0.00 & 0.00 \\ 0.00 & 0.40 & 0.40 & 0.20 & 0.00 \\ 0.00 & 0.40 & 0.30 & 0.30 & 0.00 \\ 0.00 & 0.20 & 0.40 & 0.40 & 0.00 \\ 0.00 & 0.60 & 0.40 & 0.00 & 0.00\end{array}\right]$

Template installation risk membership matrix

$R_{2}\left[\begin{array}{lllll}0.00 & 0.40 & 0.60 & 0.00 & 0.00 \\ 0.00 & 0.00 & 0.40 & 0.60 & 0.00 \\ 0.00 & 0.00 & 0.20 & 0.80 & 0.00 \\ 0.00 & 0.00 & 0.20 & 0.40 & 1.00 \\ 0.00 & 0.00 & 0.20 & 0.60 & 0.20 \\ 0.00 & 0.00 & 0.20 & 0.60 & 0.20\end{array}\right]$

Template removal risk membership matrix

$R_{3}\left[\begin{array}{lllll}0.20 & 0.40 & 0.40 & 0.00 & 0.00 \\ 0.00 & 0.80 & 0.20 & 0.00 & 0.00\end{array}\right]$ 
From the formula $B_{i}=W_{\mathrm{I}} \cdot R_{i}$ can get following results

$\mathrm{B}_{1}=\left(\begin{array}{lllll}0.022 & 0.402 & 0.357 & 0.218 & 0.000\end{array}\right)$

$\mathrm{B}_{2}=\left(\begin{array}{lllll}0.000 & 0.017 & 0.231 & 0.542 & 0.349\end{array}\right)$

$\mathrm{B}_{3}=\left(\begin{array}{lllll}0.015 & 0.500 & 0.350 & 0.000 & 0.000\end{array}\right)$

From the formula $\mathrm{B}=\mathrm{W} \cdot \mathrm{R}$ can get following results

$$
B=\left(\begin{array}{lllll}
0.025 & 0.140 & 0.270 & 0.420 & 0.250
\end{array}\right)
$$

Then by $C_{B_{\mathrm{i}}}=B_{i} \cdot V^{T}$ can get each risk loss score, for example

$C_{B_{1}}=B_{1} \cdot V^{T}=\left(\begin{array}{llllllll}0.022 & 0.402 & 0.357 & 0.218 & 0.000\end{array}\right) \cdot\left(\begin{array}{lllll}0.050 & 0.125 & 0.200 & 0.275 & 0.350\end{array}\right)^{T}=0.183$

\subsection{Determination of risk level}

The probability and loss score based on Bayesian network reasoning can determine the risk value of each node of the tall template construction, and then the risk level can be determined according to Table 3, as is shown in Table 6.

Table 6 Risk Event Level

\begin{tabular}{ccccc}
\hline Risk event & $\mathrm{P}$ & $\mathrm{C}$ & $\mathrm{R}$ & Risk level \\
\hline A & 0.398 & 0.420 & 0.166 & Class III \\
B1 & 0.448 & 0.183 & 0.082 & Class IV \\
B2 & 0.551 & 0.176 & 0.038 & Class III \\
B3 & 0.273 & 0.140 & 0.319 & Class IV \\
\hline
\end{tabular}

Through the model analysis, the tallest template construction B1 during the installation is at the highest risk, the overall construction risk of the tall template project is at the general risk level. This is consistent with the actual situation of this template project. The construction risk management and control should be strengthened in the construction process of the tall template. To strengthen the monitoring of risk factors, we should do a good job in risk detection and early warning work, develop appropriate safety technology management measures, clear responsibilities, the implementation of construction risk management.

\section{Conclusions}

Fuzzy Analytic Hierarchy Process is used by qualitative and quantitative methods to deal with various evaluation factors. Bayesian network method has strong visibility, and the causal relationship between Bayesian node variables is consistent with the hierarchical structure of the comprehensive evaluation index system of high template construction safety. Through the accident tree of the Bayesian network conversion, and combine with Bayesian network soft GeNie2 ,it is esay to reason and make the test results convenient and accurate. Combined with Bayesian network method and fuzzy analytic hierarchy process, we can carry out safety evaluation of high template construction, can take full account of the impact of construction safety risk factors. At the same time, we will qualitative and quantitative analysis of the combination, to avoid subjective errors, multi-factor, multi-level complex problem evaluation effect is better. Through the safety evaluation of the tall template construction, the risk factors are identified and the safety grade is divided. We designate the corresponding management method for the risk factors of different safety levels, carry on the dynamic control to the whole construction process, reduce the accident occurrence, and improve the enterprise safety management to the project.

\section{References}

[1] Rosowsky D, Huston D, Fuhr P, et al. Measuring formwork loads during construction[J]. Modern Steel Construction, 1994.

[2] Xie Nan, Zhang Jian, Zhang Li, et al.Based on the impact of concrete pouring construction load survey and statistical analysis [J]. Engineering Mechanics, 2015, 32 (2): 90-96. 
[3] Zhao jun, yang yulin.Statistical analysis and analysis of live load during construction of reinforced concrete structures [J].Journal of Guilin University of Science and Technology,2010, 30 (3): 356-359.

[4] Hadipriono F C, Wang H K. Causes of falsework collapses during construction[J]. Structural Safety, 1987, 4(3):179-195.

[5] Fan Liangyi.Application of Fault Tree Analysis in Construction Safety Management of High Scale System [J]. Construction Safety, 2013, 28 (9): 26-30.

[6] Zhang tao, chen yake, wang jiajun.Application of Gray Theory in Safety Assessment of High Scale [J]. Science and Technology Communication, 2016, 8 (13).

[7] Wang Shuangcheng. Bayesian network learning, reasoning and application [M]. Lixin Accounting Press, 2010.

[8] Yu Bo, Wang Sijing, Li Zhiyuan, et al.Fuzzy Comprehensive Evaluation Model of Electric Vehicle Based on AHP [J]. Science and Technology Innovation Bulletin, 2017 (11): 179-180. 